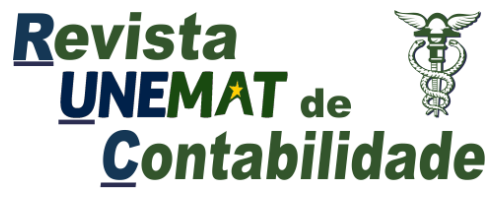

v. 10, n. 19,2021

\title{
BALANÇO DE PRODUÇÃO: Uma análise das características das publicações sobre custeio ABC nos periódicos contábeis qualificados pela CAPES como A2 e B1
}

\author{
Nome: Eliane Maria Camargo \\ Bacharel em Ciências Contábeis pela Universidade do Estado de Mato Grosso \\ Instituição: Universidade do Estado de Mato Grosso \\ E-mail: elianecac08@gmail.com
}

\section{Almir Rodrigues Durigon}

Doutor em Ciências Contábeis pela Universidade do Vale do Rio dos Sinos

Universidade do Estado de Mato Grosso

E-mail: $\underline{\text { almir@ unemat.br - https://orcid.org/0000-0002-3460-2048 }}$

\section{Juliana Vitória Vieira Mattiello da Silva}

Doutora em Administração pela Universidade do Vale do Rio dos Sinos

Universidade do Estado de Mato Grosso

E-mail: julianamattiello@unemat.br - https://orcid.org/0000-0002-7295-6541

\section{Tatiana Rosa Carvalho Ribeiro}

Mestra em Educação pela Universidade do Estado de Mato Grosso

Universidade do Estado de Mato Grosso

E-mail: tatiana.ribeiro@unemat.br - https://orcid.org/0000-0003-0722-988X

\section{RESUMO}

Este artigo tem por objetivo analisar as características das publicações sobre o método de custeio Activity-Based Costing - $A B C$, publicadas nos periódicos nacionais em contabilidade. A metodologia adotada constitui-se de pesquisa bibliográfica e de análise conteúdo. Foram analisados os artigos publicados nas edições de 2011 a 2020 dos periódicos de contabilidade qualificados pela CAPES como A2 e B1. Durante as análises, foi possível observar os autores mais citados, as obras mais referenciadas, a quantidade de autores por artigo, a formação acadêmica dos autores e os métodos de pesquisa mais utilizados nos trabalhos. Os resultados obtidos revelam que não há muitas publicações sobre o assunto, que a técnica mais adotada quanto aos procedimentos técnicos foi a pesquisa descritiva, os artigos foram publicados por mais de dois autores, o autor mais influente é Robert S. Kaplan, a obra mais referenciada foi "Custo e desempenho: Administre seus custos para ser mais competitivo". A relevância desta pesquisa está em contribuições futuras com a ampliação de investigações acerca da temática em questão.

Palavras chaves: Custeio ABC. Métodos de custeio. Bibliometria.

\section{INTRODUÇÃO}

Em razão das crescentes mudanças no cenário empresarial causadas pelo processo de globalização, o qual tem estimulado o aumento da concorrência entre as empresas, a contabilidade de custos vem se desenvolvendo notadamente. Desse modo, buscando por ferramentas que auxiliem no gerenciamento das organizações, com o intuito de mantê-las mais 


\section{Revista \\ UNEMAT de \\ Contabilidade}

v. 10, n. 19,2021

competitivas em um mercado cada vez mais globalizado e competitivo (VENTURINI et al. 2006).

De acordo com Laurindo (2002), com o mercado de trabalho sempre exposto aos desenvolvimentos tecnológicos, torna-se cada vez maior a busca por instrumentos que possam auxiliar no gerenciamento das organizações, sendo a contabilidade de custos um desses instrumentos, visto que objetiva a sobrevida das empresas com sucesso.

Conforme Vieira (2008), a contabilidade de custos teve início com a Revolução Industrial, desde o momento em que as organizações, que até então, eram mercantilistas, passaram a comprar matéria-prima para serem transformadas em novos produtos. Ainda, de acordo com Andrade, Batista e Sousa (2004), a contabilidade tem a finalidade de colocar à disposição dos gestores as informações sobre custos de seus bens, mercadorias e/ou serviços, seja a empresa do ramo industrial, comercial ou de prestação de serviços.

Sendo assim, com base na necessidade de implantação de novos métodos dentro da contabilidade de custo, surgiu o Custeio Baseado em Atividades - ABC, por volta da década de 80. Assim, tornando-se uma importante ferramenta para auxiliar em decisões gerenciais e estratégicas, com a finalidade de melhorar os serviços e avaliar inciativas de qualidade que contribuam para impulsionar as empresas e, portanto, para o melhoramento contínuo (PEREIRA et al. 2012).

Segundo Laurindo (2002), as organizações devem adotar a nova sistematização de custeio para aprimorar seu desempenho frente à concorrência. Assim, o método que vem sendo cada vez mais utilizado é o de Custeio Baseado em Atividades (ABC), que completa os sistemas mais tradicionais, como o Custeio por Absorção e o Custeio Variável, por exemplo, visto que apresenta um enfoque mais estratégico na mensuração dos custos.

De acordo com Oliveira e Aragão (2011), a realização de pesquisas sobre custos pode contribuir para a eficiência produtiva da empresa, melhorando, dessa forma, o desenvolvimento econômico e financeiro tanto da organização como da sociedade.

Para Mauss e Costi (2004), o que diferencia o método ABC dos demais é a forma como destina os custos indiretos aos produtos, resultando, assim, em um método diferenciado de calcular os custos de um dado objeto. Neste caso, podendo ser produtos, linhas de produtos, serviços, clientes, segmentos de clientes, canais de distribuição e algum outro tipo de objeto de interesse da gerência.

Nesse contexto, Rodrigues e Rosa (2006) ressaltam que o método de custeio ABC reconhece o local no qual as questões potenciais estão localizadas. Frisando-se que o que os gestores farão com os dados disponibilizados definirá o sucesso do gerenciamento de custos. Tal método demonstra-se apropriado para atender às necessidades das organizações, pois procura aperfeiçoamento constante por meio da anulação de atividades que não acrescente valor ao produto.

Nesse contexto, há inúmeros pesquisadores que se empenham em estudar o mesmo fato, seja ele em qualquer área, assim, os estudos bibliométricos se tornam mais relevantes à medida que os pesquisadores avaliam como e quem está pesquisando determinado assunto (BEUREN et. al, 2011).

Isso posto, busca-se responder ao seguinte questionamento: Qual a característica dos artigos científicos publicados nos periódicos contábeis qualificados pela CAPES como A2 e B1 no período de 2011 a 2020? Procura-se com esse questionamento avaliar o perfil das pesquisas sobre custeio $\mathrm{ABC}$ e identificar quais são os aspectos abordados pelos autores sobre o assunto. Para responder esta questão, o objetivo geral deste artigo baseia-se em analisar as características das publicações referentes a custeio $\mathrm{ABC}$ publicadas nos periódicos de contabilidade qualificados pela CAPES como A2 e B1 no período de 2011 a 2020. 


\section{Revista \\ UNEMAT de \\ Contabilidade}

v. 10, n. 19,2021

Este estudo permite observar os avanços teóricos e práticos sobre o tema dando visibilidade a produção cientifica da área de contabilidade de custos produzida no Brasil. Considerando as limitações, por utilizar como amostra apenas periódicos nacionais qualificados pela CAPES, alerta-se que os resultados dessa pesquisa não podem ser generalizados para outros veículos de publicações nem para outras áreas. O objetivo deste trabalho é entender e explicar as características das publicações nos periódicos específicos. Contudo, se observa que os achados da pesquisa podem contribuir pra o entendimento da produção cientifica da área de contabilidade de custos, uma vez que os periódicos contábeis qualificados pela CAPES são locais de importantes discussões para o desenvolvimento científico do tema.

Após explanação dessas considerações iniciais e com intuito de atingir o objetivo proposto, o presente artigo, na sequência, apresenta referencial teórico, sucedido pela apresentação da metodologia utilizada, análise dos dados e, por último, as considerações finais e referências.

\section{FUNDAMENTAÇÃO TEÓRICA}

\subsection{Métodos de custeio}

De acordo com Martins (2003), a contabilidade de custos surgiu por meio da contabilidade financeira, em razão da necessidade de se avaliar os estoques da indústria. Para Beuren (1993), a contabilidade de custos deve estar em um constante desenvolvimento de técnicas e procedimentos para atender as necessidades dos usuários, desse modo, fornecendo informações que sejam úteis com relação aos custos da empresa.

Segundo Beuren et al. (2011), é na contabilidade de custo que são geradas informações que auxiliam na melhoria dos processos, bem como na qualidade da produção, administração, gestão ambiental, decisões mercadológicas, no planejamento, no controle e na tomada de decisão estratégica.

Conforme Vieira (2008), a contabilidade de custos coleta, classifica e registra tanto os dados internos operacionais das diversas atividades da entidade, bem como, em algumas vezes, coleta e organiza também os dados externos. Esses dados coletados podem ser tanto monetários como físicos. A combinação dos dois resulta em indicadores gerenciais com grande poder de informação.

De acordo com Beuren et. al (2011), existem diversos métodos de custeio disponíveis na literatura, sendo utilizados de maneira individual ou de forma conjunta. Para Mauss e Costi (2004), os métodos de custeio não nasceram prontos, mas foram evoluindo conforme as demandas do mercado. Essa situação leva a compreender que a Contabilidade de Custos e os métodos de custeio jamais alcançarão uma forma definitiva, visto que, como todo mecanismo que serve de apoio ao administrativo, refere-se a estruturas dinâmicas, por isso, vivem em constante evolução.

Nesse sentido, Abbas, Gonçalves e Leoncine (2012) conceituam os métodos de custeio como ferramentas de grande importância, pois geram informações que auxiliam na tomada de decisões. Para Beuren et al. (2011), os métodos de custeio são importantes para o processo de gestão. Assim, nas últimas décadas, eles vêm aumentando sua capacidade de geração de informação.

Esses métodos são utilizados para, entre muitas outras informações, determinar o valor dos objetos de custeio; reduzir custos, melhorar os processos; eliminar desperdícios; decidir entre produzir ou terceirizar; 


\section{Revista \\ UNEMAT de \\ Contabilidade}

e eliminar, criar e aumentar, ou diminuir, a linha de produção de certos produtos (ABBAS, GONÇALVES E LEONCINE, 2012, p.146).

Segundo Schultz, Silva e Borgert (2008), os métodos de custeio tinham como principal objetivo oferecer uma forma padronizada e objetiva de apuração e determinação dos custos totais. No entanto, com o passar do tempo, em razão da necessidade de maior precisão para a tomada de decisão, bem como do aumento na concorrência, foram desenvolvidos diversos métodos, pois as empresas necessitavam de métodos mais dinâmicos que permitissem planejar e traçar estratégias. Neste contexto, Leite (2001) destaca que a contabilidade de custos foi se adequando para ser usada como ferramenta nas tomadas de decisões dentro das organizações. Dessa forma, vários métodos de custeio foram se formando, dentre eles, destacam-se o custeio por absorção, custeio variável e o custeio $\mathrm{ABC}$.

\subsubsection{Custeio por Absorção}

A escolha apropriada do método de custeio pela empresa é fundamental, pois implica, diretamente, no resultado de seus negócios, tornando a empresa mais competitiva. A escolha correta do método de custeio e a forma como os custos são acumulados e distribuídos aos vários departamentos e/ou produtos proporcionam para a empresa maior exatidão na apuração do custo unitário e na avaliação dos resultados. (PINTO, 2010).

De acordo com Eyerkaufer, Costa e Faria (2007), o método de custeio por absorção surgiu por volta de 1920. Este método é o mais utilizado pelas empresas, pois segue o padrão da aplicação dos princípios contábeis geralmente aceitos. Ainda, consiste na apropriação dos gastos referentes ao esforço de produção aos produtos ou serviços, sejam eles diretos ou indiretos, fixos ou variáveis.

Segundo Martins (2003), o custeio por absorção é constituído pela apropriação dos custos da produção aos bens elaborados, neste caso, somente os de produção. Já os gastos referentes ao esforço de produção são repartidos para todos os produtos ou serviços realizados.

Neste método de custeio, todos os custos de produção são apropriados aos bens e serviços produzidos, o que enquadra todos os custos variáveis, fixos, diretos ou indiretos. Os custos diretos, através da apropriação direta, e os custos indiretos através por intermédio da atribuição com base em critérios de rateio estabelecidos (MORAES e MELLO, 2016, p 05).

De acordo com Pereira Filho e Amaral (1998), no sistema de custeio por absorção, são incluídos, de modo geral, todos os custos indiretos de fabricação de um determinado período nos custos de suas diferentes atividades industriais, sejam de produtos, de processos ou de serviços.

\subsubsection{Custeio Variável}

Entre os anos de 1905 e 1935, pesquisadores iniciaram estudos sobre um novo sistema de apuração de custos com o intuito de oferecer suporte para a gestão das organizações. Sendo assim, como resultado dessa pesquisa, surgiu o custeio variável, que considera como custo de produção somente os custos variáveis. Este método de custeio é indicado para controles gerenciais, pois apropria à produção os custos variáveis aos produtos, desse modo, o custo dos 


\section{Revista \\ UNEMAT de \\ Contabilidade}

v. 10, n. 19,2021

produtos vendidos e os estoques finais de produtos em elaboração e acabados só apresentarão custos variáveis (PINTO, 2010).

Segundo Morais e Mello (2016), são alocados nesse método de custeio os custos variáveis aos bens ou aos serviços produzidos, ou seja, todos os custos variáveis, sejam diretos ou indiretos. Já os custos fixos não integram os custos de produção dos bens ou serviços, pois são considerados como despesas.

Conforme Abbas, Gonçalves e Leoncine (2012, p. 148), no custeio variável, pressupõese que, para a organização funcionar, ela deve estar comprometida com os custos fixos, pois não serão alterados caso ocorra aumento ou diminuição da produção ou, ainda, caso não haja produção.

Para Pereira Filho e Amaral (1998), no custeio variável, só são incluídos os custos das operações, dos produtos, dos serviços, das atividades, dos custos diretos e variáveis. De acordo com Biasio (2005), neste método, só são alocados aos produtos os custos variáveis, os custos fixos ficam separados e são considerados como despesas do período, indo imediatamente para o resultado.

\subsection{Custeio ABC}

O Actívity-Based Costing, conhecido popularmente como ABC, é o Método de Custeio Baseado em Atividades. Tal método foi desenvolvido por Robert S. Kaplan e Robin Cooper, com o intuito de diminuir as alterações ocasionadas pela atribuição arbitrária dos custos indiretos. Sendo assim, o objetivo é avaliar as atividades desenvolvidas pela empresa, observando-as separadamente, para melhor identificar os custos que envolvem cada processo (MARTINS, 2003).

Conforme Tomé, Coelho e Colares (2013), o ABC possui uma forma de atribuição dos custos aos produtos e serviços. Ainda de acordo com os autores, no ABC, é possível identificar os custos por atividades, que são alocados ao produto que recebeu determinada atividade. Para Pozzebon, Martins e Junior (2017, p. 231), “o ABC parte do princípio de que não é o produto ou serviço que consome recursos, e sim os recursos são consumidos pelas atividades e estas, por sua vez, são consumidas pelos produtos ou serviços".

De acordo com Martins (2003), no método ABC, os custos são provocados pela realização das atividades, pois essas consomem recursos ao se realizarem. Os outros métodos de custeio consideram que quem consome os recursos são os objetos de custos como os produtos, os clientes etc. Para Dieh, Souza e Alves (2008), o método ABC se difere dos outros métodos, visto que busca identificar, por meio do rastreamento, a origem e a causa dos custos, para depois destiná-los aos objetos, enquanto nos métodos tradicionais isso ocorre por rateio.

$\mathrm{O}$ ABC permite uma melhor visualização dos custos por meio das análises das atividades executadas na empresa e suas ligações com os produtos. Essas atividades são ações que se utilizam de recursos humanos, materiais, financeiros e tecnológicos para a produção de bens e serviços. Portanto, sendo necessário um conjunto de tarefas para execução, indispensáveis para a concretização de um processo (MARTINS, 2003).

Custódio, Machado e Gibbon (2011) destacam como vantagens do custeio ABC o aumento dos controles, a redução de custos e os rateios arbitrários. Moraes e Mello (2016) trazem como vantagens do método $\mathrm{ABC}$ a apuração com melhor exatidão dos custos dos produtos. Assim, conseguindo identificar os direcionadores de custos e das atividades; indicando os custos que não integram valor aos produtos e aos processos; detectando informações gerenciais sobre os custos 'invisíveis' pelos métodos de custeio que são tradicionais. Já Dieh e Souza (2007) trazem como críticas ao método ABC o nível de detalhamento e sua montagem e manutenção, que é considerada muito cara. 


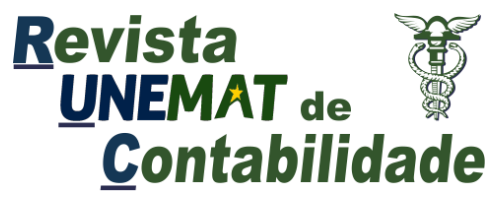

Segundo Martins (2003), para se utilizar o ABC, essencial fazer uma definição das atividades que são mais relevantes dentro dos departamentos da empresa, assim como os direcionadores de custos e de recursos que serão alocados aos diversos custos incorridos às atividades.

O ABC pode também ser aplicado em empresas não industriais, como em intuições financeiras, prestadoras de serviços públicos, escolas, hospitais, inclusive em instituições sem fins lucrativos, pois as atividades ocorrem tanto em processos quando em prestação de serviços (TOMÉ, COELHO E COLARES, 2013, p 28).

De acordo com Leite (2001), podem ocorrer algumas variações no processo de implantação do custeio $\mathrm{ABC}$, em razão da finalidade do método e das facilidades encontradas para seu desenvolvimento. Apesar disso, é possível definir de forma geral as seguintes etapas para sua implantação: primeira, a definição da finalidade e das premissas do sistema; seguida da definição de atividades; definição de direcionadores de custos; definição dos possíveis objetos de custos; custeamento das atividades; medição dos direcionadores de custo; custeamento de objetos; e a última etapa, a análise dos resultados.

Conforme Martins (2003), o método de custeio ABC pode ser entendido como uma ferramenta que analisa os fluxos dos custos. Assim, os benefícios do método ABC são maiores de acordo com a quantidade de processos interdepartamentais, isto é, quanto maiores os departamentos dentro da empresa, maiores são os seus benefícios.

\subsection{Estudos Relacionados}

O levantamento bibliográfico para a realização do trabalho selecionou algumas pesquisas com estudos relacionados ao tema abordado. No Quadro 1, estão apresentadas as obras por ordem cronológica da mais antiga para a mais recente, auxiliando na melhor compreensão das pesquisas já realizadas.

Quadro 1 - Estudos Relacionados

\begin{tabular}{|c|c|c|}
\hline Autor & Títulos & Objetivos \\
\hline $\begin{array}{l}\text { Diehl e Souza } \\
\text { (2007) }\end{array}$ & $\begin{array}{lcr}\text { Um Estudo } & \text { sobre } & \text { as } \\
\text { publicações } & \text { acerca } & \text { do } \\
\text { Custeio } & \text { Baseado } & \text { em } \\
\text { Atividades } & \text { (ABC) } & \text { no } \\
\text { Congresso } & \text { Brasileiro } & \text { de } \\
\text { Custos de 1997 a 2006. } & \end{array}$ & $\begin{array}{l}\text { Analisar as características das } \\
\text { publicações científicas sobre ABC no } \\
\text { Congresso Brasileiro de Custos. }\end{array}$ \\
\hline $\begin{array}{l}\text { Diehl, Souza e } \\
\text { Alves (2008) }\end{array}$ & $\begin{array}{l}\text { Custeio Baseado } \quad \text { em } \\
\text { Atividades (ABC): Um } \\
\text { Estudo Sobre Publicações } \\
\text { em Eventos Científicos. }\end{array}$ & $\begin{array}{l}\text { Analisar as características qualitativas } \\
\text { das publicações científicas sobre ABC } \\
\text { em edições do Congresso Brasileiro de } \\
\text { Custos. }\end{array}$ \\
\hline $\begin{array}{c}\text { Custódio, } \\
\text { Machado e } \\
\text { Gibbon (2011) } \\
\end{array}$ & $\begin{array}{l}\text { Custeio Baseado em } \\
\text { Atividades: Análise da } \\
\text { Produção Científica, sob a }\end{array}$ & Realizar uma análise da produção \\
\hline
\end{tabular}




\begin{tabular}{|c|l|l|}
\hline & $\begin{array}{l}\text { perspectiva bibliométrica e } \\
\text { sociométrica, do Congresso } \\
\text { Brasileiro de Custos, no } \\
\text { período de 2006 a 2010. }\end{array}$ & $\begin{array}{l}\text { científica sobre o Custeio Baseado em } \\
\text { Atividades, no Congresso Brasileiro de } \\
\text { Custos, no período de 2006 a 2010. }\end{array}$ \\
\hline $\begin{array}{c}\text { MÉTODO DE CUSTEIO } \\
\text { ABC APLICADO: Uma } \\
\text { pesquisa bibliométrica. }\end{array}$ & $\begin{array}{l}\text { Analisar a produção científica realizada } \\
\text { sobre o Método de Custeio Baseado em } \\
\text { Atividades, no período de 2002 a 2015, } \\
\text { a partir de pesquisas empíricas } \\
\text { publicadas em periódicos nacionais da } \\
\text { área contábil. }\end{array}$ \\
\hline Souza, Avelar e & $\begin{array}{l}\text { ATIVIDADES: Uma análise } \\
\text { das pesquisas brasileiras } \\
\text { desenvolvidas na primeira } \\
\text { década do século XXI. }\end{array}$ & $\begin{array}{l}\text { Analisar os estudos publicados sobre o } \\
\text { tema ABC entre os anos de 2001 e 2010 } \\
\text { nos principais periódicos de } \\
\text { Contabilidade, conforme classificação } \\
\text { da Coordenação de Aperfeiçoamento de } \\
\text { Pessoal de Nível Superior (CAPES). }\end{array}$ \\
\hline
\end{tabular}

Fonte: Autores, com base nas obras citadas

O estudo de Diehl e Souza (2007) concluiu que há pouca contribuição teórica dos artigos encontrados, além disso, estão muito fundamentados em materiais teóricos de livros/textos e autores clássicos. Dessa forma, notou-se que esses artigos estão, acima de tudo, voltados para a aplicação prática do ABC.

Já Diehl, Souza e Alves (2008) realizaram uma pesquisa classificada como quali-quanti, bibliográfica, descritiva e multivariada, em que puderam observar pouca contribuição teórica dos trabalhos, ainda, que estes estão baseados em livros, textos e autores clássicos. Outra característica predominante nos trabalhos analisados é a configuração como trabalho que, acima de tudo, está direcionado à descrição de casos reais de aplicação do Método de Custeio em Atividades.

Custódio, Machado e Gibbon (2011) concluíram que os artigos estavam divididos de forma uniforme entre 15 e 17 trabalhos por ano, com exceção do ano de 2010, que houve uma redução de publicações com esse tema, havendo uma grande existência de trabalhos tendo um trio como autores. A instituição que possui mais trabalhos publicados no período de estudo foi a UFMG. Observou-se um crescimento da área temática de novas tendências aplicadas na gestão dos custos, no entanto, houve uma diminuição no número de trabalhos referentes à gestão de custos em empresas de comércio e de serviços.

Souza e Barsanti (2016) fizeram uma observação acerca dos autores pesquisados, que, dentre eles, $60,18 \%$ são do gênero masculino e apenas $28,70 \%$ possuem título de doutorado A UFMG-MG foi a instituição de ensino que apresentou mais autores vinculados, a segunda foi a UFSC (SC). Dentre os trabalhos publicados existentes, tem-se que a maior parte se desenvolveu por duas ou três pessoas. Já nas referências bibliográficas, destaca-se a utilização de livros e periódicos, com preferência por fontes internacionais.

Souza, Avelar e Boina (2016) verificaram que não houve uma tendência de aumento ou de redução das publicações relacionadas ao método $\mathrm{ABC}$ no determinado período. Também, identificou-se que os estudos empíricos tiveram maior predominância sobre os estudos teóricos. Ainda, observou-se uma grande concentração da produção científica sobre $\mathrm{ABC}$ em três autores. Constatou-se que muitos autores publicaram apenas um artigo no período e, ainda, notou-se, na análise sociométrica, que não há muitos laços nas redes sociais estabelecidas entre os autores. 


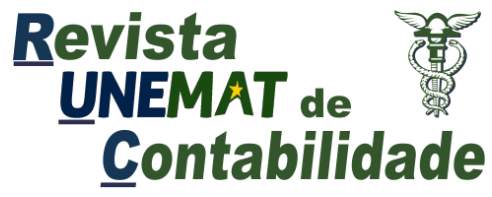

Diante do que foi exposto, julga-se que os estudos realizados por Diehl e Souza (2007), Diehl, Souza e Alves (2008), Custódio, Machado e Gibbon (2011), Souza e Barsanti (2016) e Souza, Avelar e Boina (2016), que abordam os perfis das publicações sobre o método de custeio $\mathrm{ABC}$, podem trazer grandes contribuições ao presente trabalho, tanto na construção do referencial teórico como na análise da pesquisa.

\section{METODOLOGIA}

De acordo com objetivo proposto, esta pesquisa classifica-se como pesquisa básica, pois visa a produção de conhecimento sobre publicação em contabilidade de custos. Segundo Collis e Hussey (2005) pesquisa básica é aquela que contribui com o conhecimento para o bem comum, não procura resolver um problema específico par uma organização.

Quanto à abordagem do problema a pesquisa é qualitativa, isto porque não forma utilizadas técnicas avançadas de estatística. Ainda que haja alguma mensuração, o corpus de análise trata-se de um pequeno grupo de indivíduos, não caracterizando estudo quantitativo.

No que concerne ao método utilizado foi a pesquisa bibliográfica, isto é, o problema de pesquisa foi respondido com base em referenciais teóricos publicados em documentos, neste caso, artigos científicos. Conforme Gil (2008), na pesquisa bibliográfica, utiliza-se todo o material já elaborado, que é constituído de livros e artigos científicos.

Para a coleta dos dados, foram selecionados, nas revistas on-line de contabilidade, qualificados pela CAPES como A2 e B1, com publicações no período de 2011 a 2020.

As informações da classificação dos periódicos foram obtidas mediante consulta à plataforma Sucupira, em que está disponível a qualificação das revistas. Após acesso à planilha, foi realizado o filtro de busca por periódicos nacionais em Contabilidade com a qualificação desejada, que teve como resultado um total de 16 periódicos, conforme descrito no Quadro 2.

Quadro 2: Periódicos Selecionados

\begin{tabular}{|c|c|c|}
\hline PERIÓDICO & INSTITUIÇÃO & QUALIS \\
\hline $\begin{array}{c}\text { CONTABILIDADE VISTA } \\
\text { REVISTA }\end{array}$ & UFMG/MG & $\mathrm{A} 2$ \\
\hline $\begin{array}{c}\text { RCO - REVISTA DE } \\
\text { ONTABILIDADE E } \\
\text { ORGANIZAÇÕES }\end{array}$ & FEA/USP/RP \\
\hline $\begin{array}{c}\text { REVISTA } \\
\text { CONTABILIDADE \& } \\
\text { FINANÇAS (IMPRESSO) }\end{array}$ & $\mathrm{A} 2$ \\
\hline $\begin{array}{c}\text { REVISTA CONTABILIDADE } \\
\text { \& FINANÇAS (ON-LINE) }\end{array}$ & USP/SP \\
\hline $\begin{array}{c}\text { REVISTA CONTEMPORÂNEA } \\
\text { DE CONTABILIDADE }\end{array}$ & USP/SP & $\mathrm{A} 2$ \\
\hline $\begin{array}{c}\text { REVISTA CONTEMPORÂNEA } \\
\text { DE CONTABILIDADE (UFSC) }\end{array}$ & UFSC/SC \\
\hline $\begin{array}{c}\text { REVISTA DE } \\
\text { CONTABILIDADE E } \\
\text { ORGANIZAÇÕES }\end{array}$ & UFSC/SC \\
\hline
\end{tabular}


Contabilidade

\begin{tabular}{|c|c|c|}
\hline $\begin{array}{c}\text { REVISTA UNIVERSO } \\
\text { CONTÁBIL }\end{array}$ & FURB/SC & $\mathrm{A} 2$ \\
\hline $\begin{array}{c}\text { REVISTA CONTABILIDADE } \\
\text { \& FINANÇAS (IMPRESSO) }\end{array}$ & FEA/USP & $\mathrm{A} 2$ \\
\hline $\begin{array}{c}\text { REVISTA CONTABILIDADE } \\
\text { \& FINANÇAS (ONLINE) }\end{array}$ & FEA/USP & $\mathrm{A} 2$ \\
\hline $\begin{array}{c}\text { BASE - REVISTA DE } \\
\text { ADMINISTRAÇÃO E } \\
\text { CONTABILIDADE DA } \\
\text { UNISINOS }\end{array}$ & UNISINOS/RS \\
\hline $\begin{array}{c}\text { CONTABILIDAD Y } \\
\text { NEGCIOS }\end{array}$ & PUCP/PERÚ \\
\hline $\begin{array}{c}\text { CONTABILIDADE, GESTÃO E } \\
\text { GOVERNANÇA }\end{array}$ & UNB/DF & $\mathrm{B} 1$ \\
\hline $\begin{array}{c}\text { REPEC - REVISTA DE } \\
\text { EDUCAÇÃO E PESQUISA EM } \\
\text { CONTABILIDADE }\end{array}$ & ABRACICON/DF & $\mathrm{B} 1$ \\
\hline UNB CONTÁBIL & UNB/DF & $\mathrm{B} 1$ \\
\hline $\begin{array}{c}\text { CONTABILIDADE, GESTÃO E } \\
\text { GOVERNANÇA }\end{array}$ & UNB/DF & $\mathrm{B} 1$ \\
\hline
\end{tabular}

Fonte: Dados da Pesquisa (2021)

Após a seleção dos periódicos, fez-se a busca dos artigos que tivessem a expressão "ABC" no título, resumo e nas palavras-chave. Em seguida, iniciou-se a leitura a fim de verificar a conformidade do trabalho com o tema-objeto da pesquisa. Assim, foi possível identificar 35 trabalhos, sendo somente 11 produções científicas que estavam alinhadas ao tema abordado. 


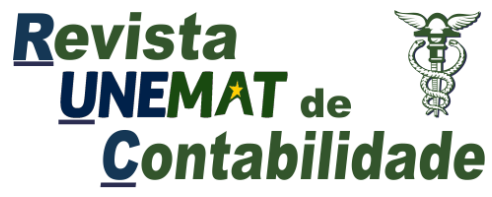

v. 10, n. 19,2021

\section{RESULTADOS E ANÁLISES}

\subsection{AUTOR QUE MAIS PUBLICA SOBRE ABC}

Ao analisar os periódicos contábeis, foram encontradas 35 revistas com qualificação A2 e B1, dentre elas, apenas 05 revistas possuíam artigos sobre custeio ABC, publicados no período de 2011 a 2020. Nas revistas selecionadas, foram identificados 11 artigos que abordam os requisitos estabelecidos, sendo 03 em idioma estrangeiro, distribuídos na tabela 1, por título e autores.

Tabela 1 - Títulos e autores dos artigos

\begin{tabular}{|c|c|}
\hline ARTIGOS & AUTORES \\
\hline $\begin{array}{l}\text { "Mensuração de Custos Intangíveis: uma } \\
\text { análise prática" (2011). }\end{array}$ & $\begin{array}{l}\text { ABREU, Adriana Leal, } \\
\text { DIEHL, Carlos Alberto, } \\
\text { MACAGNAN, Clea Beatriz. }\end{array}$ \\
\hline $\begin{array}{c}\text { "INSTITUCIONALIZAÇÃO DE } \\
\text { INSTRUMENTOS DE CUSTEIO: O caso } \\
\text { de uma organização do setor elétrico } \\
\text { brasileiro" (2012). }\end{array}$ & $\begin{array}{l}\text { SANTANA, Gislaine Aparecida da Silva, } \\
\text { COLAUTO, Romualdo Douglas, } \\
\text { CARRIERI, Alexandre de Pádua. }\end{array}$ \\
\hline $\begin{array}{l}\text { "Planejamento e Controle Orçamentário em } \\
\text { Empresas Concessionárias de Rodovias: } \\
\text { Uma Pesquisa Empírica" (2012). }\end{array}$ & $\begin{array}{l}\text { PEREIRA, Fábio de Azevedo, } \\
\text { ESPEJO, Márcia Maria dos Santos } \\
\text { Bortolocci. }\end{array}$ \\
\hline $\begin{array}{l}\text { "Custos na Administração Pública: revisão } \\
\text { focada na publicação de artigos científicos a } \\
\text { partir da promulgação da Lei de } \\
\text { Responsabilidade Fiscal" (2012). }\end{array}$ & $\begin{array}{l}\text { CARNEIRO, Alexandre de Freitas, } \\
\text { SILVA NETO, José Moreira da, } \\
\text { LOCKS, Rosilene, } \\
\text { SANTOS, Maria Madalena Alves dos. }\end{array}$ \\
\hline $\begin{array}{l}\text { "Conhecimento de Custeio Baseado em } \\
\text { Atividades: estudo empírico sobre empresas } \\
\text { de pequeno e médio porte" (2012). }\end{array}$ & MACHADO, Maria João Cardoso Vieira. \\
\hline $\begin{array}{c}\text { "Custeio das Atividades das técnicas de } \\
\text { nucleação implantadas nas clareiras abertas } \\
\text { pela exploração petrolífera na Amazônia } \\
\text { central” (2013). }\end{array}$ & $\begin{array}{c}\text { BENTO, Ricardo Aparecido, } \\
\text { VIEIRA, Gil, } \\
\text { PANHOCA, Luiz, } \\
\text { CARNEIRO, Leandro Marcondes, } \\
\text { GUERRA, Celeste Martina Skewes. }\end{array}$ \\
\hline $\begin{array}{l}\text { "Práticas de gestão de custos logísticos: } \\
\text { estudo de caso em uma empresa do setor de } \\
\text { bebidas" (2014). }\end{array}$ & $\begin{array}{l}\text { SOUZA, Marcos Antonio, } \\
\text { REMPEL, Cristiano, } \\
\text { SILVA, Jorge Luiz Rosa. }\end{array}$ \\
\hline $\begin{array}{l}\text { "Análise bibliométrica de trabalhos } \\
\text { acadêmicos sobre o Time-Driven Activity- } \\
\text { Based Costing publicados em periódicos } \\
\text { entre os anos de } 2004 \text { e 2013" (2015). }\end{array}$ & $\begin{array}{l}\text { BOINA, Terence Machado, } \\
\text { AVELAR, Ewerton Alex, } \\
\text { SOUZA, Antônio Artur de, } \\
\text { RIBEIRO, Lívia Maria de Pádua. }\end{array}$ \\
\hline $\begin{array}{l}\text { "Gestão de Custos da Logística Verde: } \\
\text { Análise Exploratória das Contribuições } \\
\text { Empírico-Teóricas de Pesquisa" (2016). }\end{array}$ & $\begin{array}{l}\text { SOUZA, Marcos Antônio de, } \\
\text { MACHADO, Débora Gomes, } \\
\text { RECKZIEGEL, Valmor, } \\
\text { ALMEIDA, Lauro Brito de. }\end{array}$ \\
\hline $\begin{array}{l}\text { "DESINSTITUCIONALIZAÇÃO DO } \\
\text { CUSTO BASEADO EM ATIVIDADES: }\end{array}$ & $\begin{array}{l}\text { AILLÓN, Humberto Silva, } \\
\text { ROCHA, Welington, }\end{array}$ \\
\hline
\end{tabular}


Análise na perspectiva da nova sociologia institucional" (2018).

MARQUES, Kelly Cristina Mucio.

"Mensuração da ociosidade fabril pelos
métodos ABC, TDABC e UEP" (2019).

WERNKE, Rodney, JUNGES, Ivone, ZANIN, Antonio.

Fonte: Dados da Pesquisa

Observa-se que o autor SOUZA (Marcos Antônio de) é o único que possui mais de um artigo publicado nessa mesma temática. Nota-se também que dentre os trinta e quatro autores dos artigos selecionados, vinte e dois são do sexo masculino e doze do sexo feminino.

\subsection{MÉTODOS DE PESQUISA UTILIZADOS}

No quadro 3, são apresentadas as principais descrições dos 11 artigos selecionados, tais como o ano, o título da obra e o método de pesquisa utilizado.

Quadro 3 - Método de pesquisa dos artigos publicados nos periódicos contábeis

\begin{tabular}{|c|c|c|}
\hline ANO & OBRAS & $\begin{array}{l}\text { MÉTODO DE } \\
\text { PESQUISA }\end{array}$ \\
\hline 2011 & $\begin{array}{l}\text { "Mensuração de Custos Intangíveis: uma análise } \\
\text { prática" }\end{array}$ & $\begin{array}{l}\text { Exploratório, aplicado, } \\
\text { quali-quantitativo, estudo } \\
\text { de caso. }\end{array}$ \\
\hline 2012 & $\begin{array}{l}\text { "INSTITUCIONALIZAÇÃO DE INSTRUMENTOS } \\
\text { DE CUSTEIO: O caso de uma organização do setor } \\
\text { elétrico brasileiro" }\end{array}$ & $\begin{array}{l}\text { Descritiva, explicativa, } \\
\text { estudo de caso, qualitativa. }\end{array}$ \\
\hline 2012 & $\begin{array}{l}\text { "Planejamento e Controle Orçamentário em } \\
\text { Empresas Concessionárias de Rodovias: Uma } \\
\text { Pesquisa Empírica" }\end{array}$ & $\begin{array}{l}\text { Descritiva, quantitativo e } \\
\text { survey. }\end{array}$ \\
\hline 2012 & $\begin{array}{l}\text { "Custos na Administração Pública: revisão focada na } \\
\text { publicação de artigos científicos a partir da } \\
\text { promulgação da Lei de Responsabilidade Fiscal" }\end{array}$ & $\begin{array}{l}\text { Descritiva, exploratória, } \\
\text { bibliográfica e qualitativa. }\end{array}$ \\
\hline 2012 & $\begin{array}{l}\text { "Conhecimento de Custeio Baseado em Atividades: } \\
\text { estudo empírico sobre empresas de pequeno e médio } \\
\text { porte" }\end{array}$ & Estudo de caso. \\
\hline 2013 & $\begin{array}{l}\text { "Custeio das Atividades das técnicas de nucleação } \\
\text { implantadas nas clareiras abertas pela exploração } \\
\text { petrolífera na Amazônia central" }\end{array}$ & Estudo de caso. \\
\hline 2014 & $\begin{array}{l}\text { "Práticas de gestão de custos logísticos: estudo de } \\
\text { caso em uma empresa do setor de bebidas" }\end{array}$ & $\begin{array}{l}\text { Descritiva, exploratória } \\
\text { qualitativa, estudo de caso e } \\
\text { pesquisa documental. }\end{array}$ \\
\hline 2015 & $\begin{array}{l}\text { "Análise bibliométrica de trabalhos acadêmicos sobre } \\
\text { o Time-Driven Activity-Based Costing publicados } \\
\text { em periódicos entre os anos de } 2004 \text { e } 2013 "\end{array}$ & Quantitativa e descritiva. \\
\hline 2016 & $\begin{array}{l}\text { "Gestão de Custos da Logística Verde: Análise } \\
\text { Exploratória das Contribuições Empírico-Teóricas de } \\
\text { Pesquisa" }\end{array}$ & $\begin{array}{l}\text { Exploratória, descritiva, } \\
\text { bibliográfica e qualitativa. }\end{array}$ \\
\hline
\end{tabular}




\begin{tabular}{|c|l|l|}
\hline 2018 & $\begin{array}{l}\text { "DESINSTITUCIONALIZAÇÃO DO CUSTO } \\
\text { BASEADO EM ATIVIDADES: Análise na } \\
\text { perspectiva da nova sociologia institucional" }\end{array}$ & $\begin{array}{l}\text { Estudo de casos múltiplos, } \\
\text { pesquisa documental. }\end{array}$ \\
\hline 2019 & $\begin{array}{l}\text { "Mensuração da ociosidade fabril pelos métodos } \\
\text { ABC, TDABC e UEP" }\end{array}$ & $\begin{array}{l}\text { Estudo de caso, qualitativo } \\
\text { e descritiva. }\end{array}$ \\
\hline
\end{tabular}

Fonte: Dados da Pesquisa

Observa-se, na tabela 3, que 2012 foi o ano com o maior número de publicações sobre custeio $\mathrm{ABC}$, visto que foram 4 artigos publicados nesse mesmo ano. No entanto, nota-se que nos outros anos houve apenas uma publicação por ano. Já com relação aos métodos de pesquisa mais utilizados, destacam-se em primeiro a pesquisa descritiva, seguida do estudo de casos e, por fim, a pesquisa qualitativa.

Os resultados desta análise reafirmam a pesquisa de Souza e Barsanti (2016), visto que, dentre os métodos mais utilizados, também demonstraram a pesquisa descritiva, o estudo de casos e a pesquisa qualitativa, sendo o estudo de caso o procedimento mais utilizado, citado em pouco mais de $73 \%$ das pesquisas.

\subsection{AUTOORES MAIS CITADOS}

A seguir, na tabela 2, é possível observar os autores mais referenciados nos artigos analisados, bem como a frequência com que esses autores são citados. Foram no total observadas 859 citações, entretanto, foram selecionados apenas os autores que foram citados mais de 5 vezes.

Tabela 2 - Autores mais citados

\begin{tabular}{l|c}
\hline NOME DOS AUTORES & $\begin{array}{r}\text { FREQUÊNCIA } \\
\text { ABSOLUTA }\end{array}$ \\
\hline Robert S. Kaplan & 18 \\
\hline Marcos A. de Souza & 8 \\
\hline Robin Cooper & 7 \\
\hline Elizeu Martins & 6 \\
\hline Robert W. Scapens & 6 \\
\hline Welington Rocha & 5 \\
\hline John K. SHANK & 5 \\
\hline
\end{tabular}

Fonte: Dados da Pesquisa

De acordo com o que foi apresentado na tabela, dentre os 7 autores mencionados, o mais referenciado é Robert S. Kaplan, que é citado 18 vezes ao todo. Logo depois, com 8 citações, vem Marcos A. de Souza, seguido de Robin Cooper.

\subsection{OBRAS MAIS CITADAS}

$\mathrm{Na}$ tabela 3, estão listadas as obras mais citadas nos artigos sobre custeio ABC encontrados nos periódicos contábeis no período estabelecido. Foram identificadas 478 


\section{Revista \\ UNEMAT de \\ Contabilidade}

v. 10, n. 19,2021

citações, no entanto, só foram consideradas as obras citadas mais de duas vezes, conforme mostra a tabela abaixo.

Tabela 3 - Obras mais citadas

\begin{tabular}{|c|c|}
\hline OBRAS & CITAÇÕES \\
\hline $\begin{array}{l}\text { Custo e desempenho: Administre seus custos para ser mais competitivo. São } \\
\text { Paulo: Futura, } 1998 \text {. }\end{array}$ & 3 \\
\hline $\begin{array}{l}\text { Uma Aplicação do Time-Driven ABC Model no Setor de Serviço Hospitalar: } \\
\text { A nova abordagem do ABC proposta por Kaplan e Anderson. Contabilidade } \\
\text { Vista \& Revista, v. } 18, \text { n. } 2 \text {, p. } 11-34,2007 \text {. }\end{array}$ & 3 \\
\hline $\begin{array}{l}\text { ABC: Adopters, supporters, deniers and unawares. Managerial Auditing } \\
\text { Journal, v. } 20 \text {, n. 9, p. 981-1000, } 2005 \text {. }\end{array}$ & 2 \\
\hline $\begin{array}{l}\text { Activity-based management of logistic costs in a manufacturing company: A } \\
\text { case of increased visibility of logistic costs in a Slovenian paper } \\
\text { manufacturing company. Promet - Traffic\&Transportation. v. } 24, \text { n. 1, p. 15- } \\
24,2012 \text {. }\end{array}$ & 2 \\
\hline $\begin{array}{l}\text { An empirical analysis of firms implementation experiences with activity- } \\
\text { based costing. Journal of Management Accounting Research, v. 7, n.1, p. 1- } \\
28,1995 \text {. }\end{array}$ & 2 \\
\hline $\begin{array}{l}\text { Análise gerencial de custos: aplicação em empresas modernas. 2. ed. São } \\
\text { Paulo: Atlas, } 2009 \text {. }\end{array}$ & 2 \\
\hline Contabilidade Gerencial. 2. ed. São Paulo: Atlas, 2008. & 2 \\
\hline $\begin{array}{l}\text { Cost Management in Sri Lanka: A Case Study on Volume, Activity and Time } \\
\text { as Cost Drivers. The International Journal of Accounting, v.47, n.3, p. 281- } \\
301,2012 \text {. }\end{array}$ & 2 \\
\hline $\begin{array}{l}\text { Gestão de custos: uma abordagem integrada entre contabilidade, engenharia } \\
\text { e administração. São Paulo: Atlas, } 2009 .\end{array}$ & 2 \\
\hline $\begin{array}{l}\text { Identifying operational improvements during the design process of a time- } \\
\text { driven ABC system: The role of collective worker participation and } \\
\text { leadership style. Management Accounting Research, v. 21, n. 3, p. 185-199, } \\
2010 \text {. }\end{array}$ & 2 \\
\hline Institutions and organizations. Thousand Oaks, California: Sage, 2001. & 2 \\
\hline $\begin{array}{l}\text { Time-driven Activity-Based Costing. Harvard Business Review, v. 82, n. 11, } \\
\text { p. 131-138, } 2004 .\end{array}$ & 2 \\
\hline
\end{tabular}

Fonte: Dados da Pesquisa

Feita a análise da tabela 3, verifica-se que a obra mais citada dentre os artigos é a obra de Robert S. Kaplan e Robin Cooper, intitulada Custo e desempenho: Administre seus custos para ser mais competitivo, sendo citada 3 vezes. Logo em seguida, também com 3 citações, aparece a obra Uma Aplicação do Time-Driven ABC Model no Setor de Serviço Hospitalar: A nova abordagem do ABC proposta por Kaplan e Anderson, que tem como autores Flávia Záboli Dalmácio, Amaury José Rezende e Andson Braga de Aguiar.

Desse modo, ao comparar a tabela 2 com a tabela 3 , nota-se que a obra mais citada foi Custo e desempenho: Administre seus custos para ser mais competitivo, de autoria do primeiro e terceiro autores mais citados, neste caso, Robert S. Kaplan e Robin Cooper. 


\subsection{NÚMERO DE AUTORES POR ARTIGO}

Na tabela 4, demonstra-se a distribuição de autor por artigos. É possível observar que, dentre os 11 artigos encontrados, a maior parte foi publicada por 3 autores; logo em seguida, os que possuem acima de 3 autores; também, podemos observar que dentre os artigos selecionados apenas um artigo possui um único autor.

Os resultados dessa análise correspondem aos trabalhos de Custódio, Machado e Gibbon (2011), os quais avaliaram que a maioria dos artigos analisados possuíam três autores, sendo $37 \%$ do total estudado.

Tabela 4 - Número de autores por artigo.

\begin{tabular}{c|c|c}
\hline $\begin{array}{c}\text { NÚMERO DE } \\
\text { AUTORES }\end{array}$ & $\begin{array}{c}\text { QUANTIDADE DE } \\
\text { ARTIGOS }\end{array}$ & TOTAL \\
\hline 1 autor & 1 & 1 \\
\hline 2 autores & 1 & 1 \\
\hline 3 autores & 5 & 5 \\
\hline Acima de 3 autores & 4 & 4 \\
\hline Total & 11 & 11
\end{tabular}

Fonte: Dados da Pesquisa

\subsection{QUALIFICAÇÃO PROFISSIONAL E ÁREA DE ATUAÇÃO DOS AUTORES}

As informações quanto à titulação dos autores e suas áreas de atuação estão descritas na tabela 5. Observa-se que, dentre os trinta e quatro autores analisados, vinte e um deles possuem titulação de doutorado, seguido de sete com titulação de mestrado.

Tabela 5 - Qualificação profissional e área de atuação dos autores

\begin{tabular}{|c|c|c|c|}
\hline AUTORES & TITULAÇÃO & $\begin{array}{c}\text { INSTITUIÇÃO } \\
\text { DE } \\
\text { OBTENÇÃO } \\
\text { DO TÍTULO }\end{array}$ & $\begin{array}{c}\text { INSTITUIÇÃO } \\
\text { EM QUE } \\
\text { TRABALHA }\end{array}$ \\
\hline Humberto Silva Aillón & $\begin{array}{c}\text { Mestre em Controladoria } \\
\text { e Contabilidade }\end{array}$ & FEA/USP & $\begin{array}{l}\text { FEAC/USP - } \\
\text { Docente }\end{array}$ \\
\hline Welington Rocha & $\begin{array}{c}\text { Doutor em } \\
\text { Controladoria e } \\
\text { Contabilidade }\end{array}$ & FEA/USP & $\begin{array}{l}\text { FIPECAFI - } \\
\text { Docente }\end{array}$ \\
\hline $\begin{array}{c}\text { Kelly Cristina Mucio } \\
\text { Marques }\end{array}$ & $\begin{array}{c}\text { Doutor em } \\
\text { Controladoria e } \\
\text { Contabilidade }\end{array}$ & USP & UEM - Docente \\
\hline Adriana Leal Abreu & $\begin{array}{c}\text { Doutora em Políticas } \\
\text { Públicas } \\
\end{array}$ & UFRGS & UERGS - Docente \\
\hline Carlos Alberto Diehl & $\begin{array}{c}\text { Doutor em Engenharia } \\
\text { de Produção }\end{array}$ & UFSC & $\begin{array}{l}\text { UNISINOS - } \\
\text { Docente }\end{array}$ \\
\hline Clea Beatriz Macagnan & Pós-Doutorado & MIT & $\begin{array}{l}\text { UNISINOS - } \\
\text { Docente }\end{array}$ \\
\hline
\end{tabular}




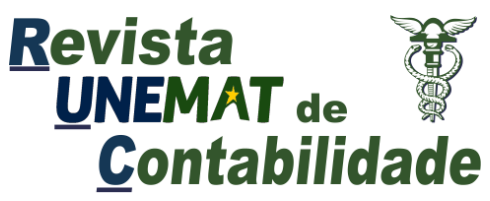

v. 10, n. 19,2021

\begin{tabular}{|c|c|c|c|}
\hline $\begin{array}{l}\text { Ricardo Aparecido } \\
\text { Bento }\end{array}$ & $\begin{array}{c}\text { Doutor em andamento } \\
\text { em Ciências de Florestas } \\
\text { Tropicais }\end{array}$ & INPA & IFAM - Docente \\
\hline Gil vieira & $\begin{array}{l}\text { Doutor em Ecologia } \\
\text { Tropical. }\end{array}$ & OXON & INPA - Docente \\
\hline Luiz Panhoca & Pós-Doutorado & UFPR & UFPR - Docente \\
\hline $\begin{array}{c}\text { Leandro Marcondes } \\
\text { Carneiro }\end{array}$ & $\begin{array}{c}\text { Doutor em } \\
\text { Contabilidade }\end{array}$ & UFPR & UEA - Docente \\
\hline $\begin{array}{c}\text { Celeste Martina Skewes } \\
\text { Guerra }\end{array}$ & $\begin{array}{l}\text { Mestre em Estudos } \\
\text { Latino-Americanos }\end{array}$ & UNILA & $\begin{array}{l}\text { Dados não } \\
\text { informados }\end{array}$ \\
\hline $\begin{array}{c}\text { Terence Machado } \\
\text { Boina }\end{array}$ & $\begin{array}{l}\text { Mestre em Ciências } \\
\text { Contábeis }\end{array}$ & UFRJ & $\begin{array}{c}\text { ANCINE - } \\
\text { Analista } \\
\text { Administrativo }\end{array}$ \\
\hline Ewerton Alex Avelar & $\begin{array}{c}\text { Doutor em } \\
\text { Administração }\end{array}$ & UFMG & UFMG - Docente \\
\hline Antônio Artur de Souza & Pós-Doutorado & Grenoble-Univ & UFMG - Docente \\
\hline $\begin{array}{c}\text { Lívia Maria de Pádua } \\
\text { Ribeiro }\end{array}$ & $\begin{array}{c}\text { Doutor em } \\
\text { Administração }\end{array}$ & UFLA & $\begin{array}{l}\text { CEFET/MG - } \\
\text { Docente }\end{array}$ \\
\hline Rodney Wernke & $\begin{array}{c}\text { Doutor em Engenharia } \\
\text { de Produção }\end{array}$ & UFSC & $\begin{array}{l}\text { UNISUL - } \\
\text { Docente }\end{array}$ \\
\hline Ivone Junges & $\begin{array}{c}\text { Doutor em Engenharia } \\
\text { de Produção }\end{array}$ & UFSC & $\begin{array}{l}\text { UNISUL - } \\
\text { Docente }\end{array}$ \\
\hline Antonio Zanin & $\begin{array}{c}\text { Doutor em Engenharia } \\
\text { de Produção }\end{array}$ & UFRGS & $\begin{array}{l}\text { UNOCHAPECO - } \\
\text { Docente }\end{array}$ \\
\hline Marcos Antonio Souza & $\begin{array}{l}\text { Doutor em } \\
\text { Controladoria e } \\
\text { Contabilidade } \\
\end{array}$ & FEA-USP & UFU - Docente \\
\hline Cristiano Rempel & $\begin{array}{l}\text { Mestre em Ciências } \\
\text { Contábeis }\end{array}$ & UNISINOS & $\begin{array}{c}\text { Bebidas Fruki S/A, } \\
\text { FRUKI - Analista } \\
\text { de Contabilidade }\end{array}$ \\
\hline Jorge Luiz Rosa Silva & $\begin{array}{l}\text { Doutor em andamento } \\
\text { em Ciências Contábeis }\end{array}$ & UNISINOS & $\begin{array}{c}\text { FBT/INEJE - } \\
\text { Coordenador do } \\
\text { MBA de Finanças } \\
\text { e Tributação }\end{array}$ \\
\hline $\begin{array}{c}\text { Alexandre de Freitas } \\
\text { Carneiro }\end{array}$ & $\begin{array}{c}\text { Doutor em } \\
\text { Administração }\end{array}$ & UNAM & UNIR - Docente \\
\hline $\begin{array}{l}\text { José Moreira da Silva } \\
\text { Neto }\end{array}$ & $\begin{array}{c}\text { Doutor em Engenharia } \\
\text { de Produção }\end{array}$ & UFSC & UNIR - Docente \\
\hline Rosilene Locks & $\begin{array}{c}\text { Mestre em } \\
\text { Administração }\end{array}$ & UNIR & UNIR - Docente \\
\hline $\begin{array}{l}\text { Maria Madalena Alves } \\
\text { dos Santos }\end{array}$ & $\begin{array}{c}\text { Mestre em } \\
\text { Administração }\end{array}$ & UNIR & $\begin{array}{c}\text { UNIR - } \\
\text { Pesquisadora }\end{array}$ \\
\hline $\begin{array}{c}\text { Fábio de Azevedo } \\
\text { Pereira } \\
\end{array}$ & $\begin{array}{c}\text { Especialista em } \\
\text { Controladoria }\end{array}$ & UFPR & IFSP - Docente \\
\hline $\begin{array}{l}\text { Márcia Maria dos } \\
\text { Santos Bortolocci } \\
\text { Espejo }\end{array}$ & $\begin{array}{c}\text { Doutor em } \\
\text { Controladoria e } \\
\text { Contabilidade }\end{array}$ & USP & UFMS - Docente \\
\hline
\end{tabular}




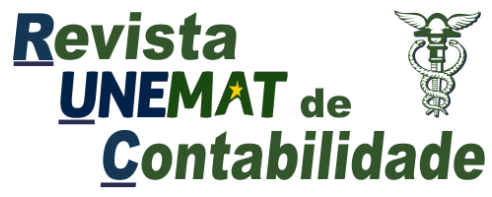

v. 10, n. 19,2021

\begin{tabular}{|c|c|c|c|}
\hline $\begin{array}{c}\text { Maria João Cardoso } \\
\text { Vieira Machado }\end{array}$ & $\begin{array}{c}\text { Doutor em } \\
\text { Contabilidade }\end{array}$ & ISCTE-IUL & $\begin{array}{l}\text { ISCTE-IUL - } \\
\text { Docente }\end{array}$ \\
\hline $\begin{array}{l}\text { Gislaine Aparecida da } \\
\text { Silva Santana }\end{array}$ & $\begin{array}{l}\text { Mestre em Ciências } \\
\text { Contábeis }\end{array}$ & UFMG & UFV - Docente \\
\hline $\begin{array}{c}\text { Romualdo Douglas } \\
\text { Colauto }\end{array}$ & Pós-Doutorado & FEAC/USP & UFPR - Docente \\
\hline $\begin{array}{c}\text { Alexandre de Pádua } \\
\text { Carrieri }\end{array}$ & $\begin{array}{c}\text { Doutor em } \\
\text { Administração }\end{array}$ & UFMG & UFMG - Docente \\
\hline $\begin{array}{c}\text { Débora Gomes } \\
\text { Machado }\end{array}$ & $\begin{array}{c}\text { Doutora em Ciências } \\
\text { Contábeis e } \\
\text { Administração }\end{array}$ & FURB & FURB - Docente \\
\hline Valmor Reckziegel & $\begin{array}{c}\text { Doutor em } \\
\text { Administração }\end{array}$ & UNINOVE & $\begin{array}{l}\text { UNIOESTE - } \\
\text { Docente }\end{array}$ \\
\hline Lauro Brito de Almeida & Pós-Doutorado & FEAC/USP & UFPR - Docente \\
\hline
\end{tabular}

Fonte: Dados da Pesquisa

Com relação à área de atuação, a maioria dos autores ocupa a função de docente, sendo que em apenas um caso não foi possível identificar a área de atuação da autora. Também, é possível observar uma predominância maior de vínculo com as instituições de ensinos localizadas no estado de São Paulo, seguida de Paraná, Santa Catarina, Rio Grande do Sul e Minas Gerais.

Os resultados dessa pesquisa corroboram com o trabalho de Souza e Barsanti (2016), visto que identificaram que $28 \%$ dos autores analisados apresentavam titulação de doutorado; seguido por $22 \%$ de autores com mestrado; sendo a Universidade Federal de Minas Gerais (UFMG) a instituições de ensino que os autores estavam mais vinculados na época da publicação do artigo.

\section{CONSIDERAÇÕES FINAIS}

Este estudo teve como objetivo geral analisar as características das publicações científicas sobre método de Custeio Baseado em Atividades, publicados nos periódicos contábeis no período de 2011 a 2020. Para tanto, foi realizada uma busca sistematizada de artigos relacionados ao assunto, com publicação em revistas qualificadas pela CAPES como A2 e B1. Sendo assim, foram identificados 35, tendo selecionado 11 trabalhos para análise, de acordo com os critérios estabelecidos.

Logo após a seleção, foi feita uma análise bibliométrica nos 11 artigos, fundamentada nos seguintes pontos: identificar os autores mais citados; demonstrar os métodos de pesquisa utilizados pelos autores; mostrar as obras mais citadas; verificar o número de autores por artigo; e conhecer a qualificação profissional e área de atuação dos autores.

De forma geral, conclui-se que o método de Custeio Baseado em Atividades é um tema pouco publicado. Assim, a principal sustentação para essa conclusão foi a identificação de apenas onze artigos encontrados nos dezesseis periódicos nacionais contábeis. De acordo com a análise, pode-se verificar que os artigos foram publicados por mais de um autor, sendo a maioria vinculados a instituições do Estado São Paulo. Constatou-se que, dentre os artigos selecionados, os procedimentos técnicos mais utilizados na amostra são a pesquisa descritiva, o estudo de casos e a qualitativa. 


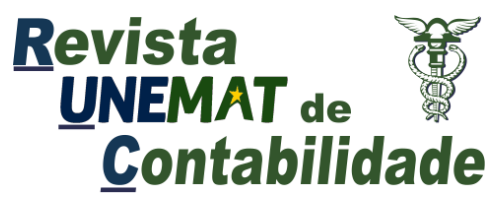

v. 10, n. 19,2021

Conforme os resultados, o autor mais referenciado é Robert S. Kaplan, sendo sua obra "Custo e desempenho: Administre seus custos para ser mais competitivo" a mais citada. Em seguida, a obra "Uma Aplicação do Time-Driven ABC Model no Setor de Serviço Hospitalar: A nova abordagem do ABC proposta por Kaplan e Anderson”, que tem como autores Flávia Záboli Dalmácio, Amaury José Rezende e Andson Braga de Aguiar.

Este trabalho trata de um estudo bibliográfico sobre o custeio $\mathrm{ABC}$, sendo, portanto, uma fonte de informação e conhecimento que poderá auxiliar acadêmicos e profissionais da área de Contabilidade.

Neste sentido, devido à ampla área de custos, também, considerando-se as limitações desta pesquisa, que utilizou apenas as publicações sobre custeio $\mathrm{ABC}$, recomenda-se uma pesquisa mais abrangente com abordagem de outros métodos de custeio, bem como estudos semelhantes a este, com base em trabalhos publicados em anais de congressos nacionais e internacionais.

\section{REFERÊNCIAS}

ABBAS, Katia; Gonçalves, MARGUIT Neumann; MAURY, Leoncine. Os Métodos de custeio: Vantagens, desvantagens e sua Aplicabilidade nos diversos tipos de organizações apresentadas pela literatura. ConTexto, Porto Alegre, v. 12, n. 22, p. 145$159,2^{\circ}$ semestre 2012. ISSN (Online): 2175-8751.

ANDRADE, Nilton de Aquino; BATISTA, Daniel Gerhard; SOUZA, Cleber Batista. Vantagens e desvantagens da utilização do sistema de custeio ABC. In: I Seminário de Gestão de Negócios, 2004, Curitiba PR. Um enfoque acadêmico da realidade empresarial. Curitiba - PR: FAE - Business School, 2004. v. 1.

BEUREN, Ilse Maria. Evolução histórica da contabilidade de custos. Conab. Vista \& Rev. Belo Horizonte, v. 5, n. 1, p. 61-66, fev. 1993.

BEUREN, Ilse Maria; SILVA, Marcia Zanievicz; SANTOS, Paulo Sérgio Almeida dos; KLOEPPEL, Nilton Roberto. Métodos de Custeio: Uma Meta-Análise dos Artigos Publicados no Congresso Brasileiro de Custos no Período de 1994 a 2010. XVIII Congresso Brasileiro de Custos - Rio de Janeiro - RJ, Brasil, 07 a 09 de novembro de 2011.

BIASIO, Roberto. Uma discussão sobre a possibilidade da unificação de vários sistemas de custeio existentes em um único sistema múltiplo de custeio, com o objetivo de agregar as vantagens e reduzir as desvantagens apresentadas quando os sistemas são utilizados isoladamente. IX Congresso Internacional de Custos - Florianópolis, SC, Brasil - 28 a 30 de novembro de 2005.

COLLIS, Jill; HUSSEY, Roger. Pesquisa em Administração: um guia prático para alunos de graduação e pós-graduação. 2 ed - Porto Alegre: Bookman, 2005.

CUSTÓDIO, Eduardo Barbosa; MACHADO, Débora Gomes; GIBBON, Artur Roberto de Oliveira. Custeio Baseado em Atividades: Análise da Produção Científica, sob a perspectiva bibliométrica e sociométrica, do Congresso Brasileiro de Custos, no Período de 2006 a 2010. XVIII Congresso Brasileiro de Custos - Rio de Janeiro - RJ, Brasil, 07 a 09 de novembro de 2011. 


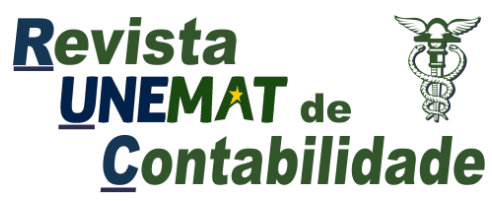

v. 10, n. 19,2021

DIEHL, Carlos Alberto; SOUZA, Marcos Antônio de. Um Estudo sobre as publicações acerca do Custeio Baseado em Atividades (ABC) no Congresso Brasileiro de Custos de 1997 à 2006. XIV Congresso Brasileiro de Custos - João Pessoa - PB, Brasil, 05 de dezembro a 07 de dezembro de 2007.

DIEHL, Carlos Alberto; SOUZA, Marcos Antônio de; ALVES, Tiago Wickstron. Custeio Baseado em Atividades (ABC): Um Estudo Sobre Publicações em Eventos Científicos. XXXII Encontro da ANPAD. Rio de Janeiro/RJ-6 a 10 de setembro de 2008.

EYERKAUFER, Marino Luiz; COSTA, Adilson; FARIA, Ana Cristina de. Métodos de custeio por absorção e variável na ovinocultura de corte: Estudo de caso em uma cabanha. Organizações Rurais \& Agroindustriais, Lavras, v. 9, n. 2, p. 202-215, 2007.

GIL, Antonio Carlos. Métodos e técnicas de pesquisa social. - 6. ed. - São Paulo: Atlas, 2008.

LAURINDO, Peterson Nery. O Kaizen e Sua Integração com o Custeio Baseado Em Atividades (ABC). IX Congresso Brasileiro de Custos - São Paulo, SP, Brasil, 13 a 15 de outubro de 2002.

LEITE, Carlos Eduardo Barros. O custeio ABC e suas aplicações. Pensar Contábil, Vol. 4, $\mathrm{N}^{\mathrm{o}} 11$ (2001).

MARCONI, Marina de Andrade; LAKATOS, Eva Maria. Fundamentos de metodologia científica. - 5. ed. - São Paulo: Atlas 2003.

MARTINS, Eliseu. Contabilidade de Custos. 9. ed. - São Paulo: Atlas, 2003.

MAUSS, C. V.; COSTI, R. M.; O Método de Custeio ABC como instrumento de gestão. ULBRA/UNISINOS; 2004. Disponível em:

https://www.aedb.br/seget/arquivos/artigos06/784_Artigo\%20Abc_Seget1.pdf. Acesso em: 11 mar.2021.

MORAIS, Kevin Luiz de Queiroz; MELLO, Ricardo Bernardes de. MÉTODOS DE CUSTEIO: sua importância na gestão dos negócios. $9^{\circ}$ Congresso Pós-Graduação UNIS. Fundação de Ensino e Pesquisa do Sul de Minas, 2016. Disponível em:http://repositório.unis.edu.br/handle/prefix/509>. Acessado em: 19/12/2020.

OLIVEIRA, Ana Caroline Peixoto; ARAGÃO, Iracema Raimunda Brito Neves. Pesquisa em Contabilidade de Custos: um estudo sobre características dos artigos publicadas nas revistas on-line brasileiras avaliadas pela Coordenação de Aperfeiçoamento de Pessoal de Nível Superior. ReAC - Revista de Administração e Contabilidade. Faculdade Anísio Teixeira (FAT), Feira de Santana-Ba, v. 3, n. 2, p. 41-56, julho/dezembro, 2011.

PEREIRA FILHO, Antônio Dias; AMARAL, Hudson Fernandes. A contabilidade de custos como instrumento de informação gerencial-um enfoque no sistema de custeio ABC. Contab. Vista \& Rev. Belo Horizonte, v. 9, n.2, p. 3-14, jun.1998.

PEREIRA, Aline Pedrosa; OLIVEIRA, Robson Ramos; LEAL, Carlos Roberto Soares; SILVA, Ualdo José da. Inserção do tema Custeio ABC em Periódicos. IX Simpósio de 


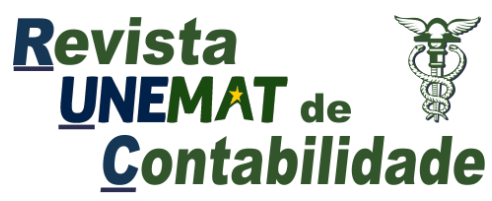

v. 10, n. 19,2021

Excelência em Gestão e Tecnologia. Tema: Gestão, Inovação e Tecnologia para a Sustentabilidade. 2012.

PINTO, Leonardo José Seixas. Comparação de resultados obtidos na aplicação dos métodos de custeio por absorção e variável: um estudo de caso. VII Simpósio de Excelência em Gestão e Tecnologia - Resende - RJ, Brasil, 20 a 23 de outubro de 2010.

POZZEBON, Mauricio Fernando; MARTINS, Vinicius Abilio; JUNIOR, Jair Jeremias. Análise de Viabilidade da Aplicação do Método de Custeio ABC em uma Empresa Prestadora de Serviços Contábeis. REPAE, São Paulo, v. 3, n. 2, mai./out. 2017. ISSN: 2447-6129.

Rodrigues C.R; Rosa P.M; O Custeio Baseado em Atividades como Instrumento de Gestão em Empresas Contábeis, XIII Congresso Brasileiro de Custos - Belo Horizonte MG, Brasil, 30 de outubro a 01 de novembro de 2006.

SCHULTZ, Charles Albino; SILVA, Marcia Zanievicz da; BORGERT, Altair. É o Custeio por Absorção o único método aceito pela Contabilidade? XV Congresso Brasileiro de Custos - Curitiba - PR, Brasil, 12 a 14 de novembro de 2008.

SILVA, Edna Lúcia da; MENEZES, Estera Muszkat. Metodologia da Pesquisa e Elaboração de Dissertação. - 3. ed. rev. atual. - Florianópolis: Laboratório de Ensino a Distância da UFSC, 2001.

SOUZA, Ângela Rozane Leal de; BARSANTI, Henrique Garcia. Método de custeio ABC aplicado: Uma pesquisa bibliométrica. Universidade Federal do Rio Grande do Sul, 2016. <http://hdl.handle.net/10183/167300>. Acessado em: 09/12/2020.

SOUZA, Antônio Artur de; AVELAR, Ewerton Alex; BOINA, Terence Machado. Custeio Baseado em Atividades: Uma análise das pesquisas brasileiras desenvolvidas na primeira década do século XXI. RIC - Revista de Informação Contábil - ISSN 1982-3967 Vol. 10, no2, p. 1-19, Abr-Jun/2016.

TOMÉ, Gustavo de Sousa; COELHO, Haryel Paiva; COLARES, Josy Larussa Meyer. o Método ABC como Instrumento da Análise Estratégica. 21 -29 · jan./dez. 2013 · n. 1 • v. 2 . Santa Luzia $\cdot \mathrm{REAC} \cdot 22$.

VENTURINI, Jonas Cardona; PEREIRA, Breno Augusto Diniz; CERETTA, Paulo Sergio; GHILARDI, Wanderlei José; COSTA, Paulo Ricardo De Jesus. Evolução dos sistemas de custeio: um enfoque à luz do sistema baseado na atividade - ABC. XIII Congresso Brasileiro de Custos - Belo Horizonte, MG, Brasil - 30 de outubro a 01 de novembro de 2006.

VIEIRA, Eusélia Paveglio. Custos e formação do preço de venda. Ijuí - Rio Grande do Sul: Ed. Unijuí, 2008. - 106 p.; il. - (Coleção educação a distância. Série livro-texto). 